\begin{tabular}{|c|c|c|c|c|}
\hline $\begin{array}{c}\text { Prosiding Penelitian \& } \\
\begin{array}{c}\text { Pengabdian Kepada } \\
\text { Masyarakat }\end{array}\end{array}$ & $\begin{array}{c}\text { e ISSN : 2581-1126 } \\
\text { p ISSN : 2442-448X }\end{array}$ & Vol 5, No: 2 & Hal: $124-131$ & Juli 2018 \\
\hline
\end{tabular}

\title{
PROFIL BURUH K3L ZONA 2 UNIVERSITAS PADJADJARAN
}

\author{
Aulia Vegianti ${ }^{1}$ dan Nurliana Cipta Apsari ${ }^{2}$
}

\author{
1. Mahasiswa Program Studi Kesejahteraan Sosial Universitas Padjadjaran \\ 2. Pusdi CSR, Kewirausahaan Sosial dan Pengembangan Masyarakat Universitas \\ Padjadjaran
}

E-mail: aulia17001@mail.unpad.ac.id dan nurliana.cipta.apsari@unpad.ac.id

\begin{abstract}
ABSTRAK
Peningkatan jumlah penduduk usia kerja pada tahun 2010 mengakibatkan penurunan pada beban ketergantungan. Dengan banyaknya penduduk pada usia produktif menjadikan Indonesia memiliki pasar tenaga kerja yang besar. Seiring dengan perkembangan zaman, kebutuhan manusia semakin meningka, begitu juga pekerja/buruh. Maka dari itu, perusahaan harus memenuhi kewajibannya dalam pemenuhan hak bagi pekerja/buruh yang pada mereka. Penelitian ini dilakukan untuk mengetahui profil K3L zona 2 Universitas Padjadjaran. Metode yang digunakan dalam penelitian ini adalah kuantitatif. Dengan menggunakan kuesioner sebagai alat pengumpulan data. Responden penelitian ini adalah para pekerja K3L Unpad yang bekerja di zona 2. Hasil penelitian menunjukkan mayoritas pekerja $\mathrm{K} 3 \mathrm{~L}$ adalah perempuan dengan tingkat pendidikan mayoritas adalah sekolah dasar.
\end{abstract}

Kata kunci: Pekerja/Buruh, K3L.

\section{PENDAHULUAN}

Menurut Data Bappenas tahun 2013, menurut susunan umur usia kerja pada tahun 2010, yaitu 15-64 tahun meningkat dari 66,5 persen menjadi 67,9 persen, yang kemudia mengakibatkan penurunan pada beban ketergantungan (interdependency ratio), yang awalnya 50,5 persen kemudian turun menjadi 47,3 persen pada tahun 2010. Besarnya tenaga kerja atau buruh tentunya harus disertai dengan pemenuhan hak-hak dan kebutuhan buruh yang harus dipenuhi oleh pengusaha, perusahaan, lembaga tempat bekerja, maupun negara. Buruh yang menggerakkan sektor ekonomi bawah yang memiliki kontribusi dalam perekonomian dan menjadi penyeimbang dan penyelamat neraca pertumbuhan ekonomi sehingga menampakkan hasil yang "membanggakan", dilihat dari kenaikan Produk Domestik Bruto (PDB) pada 2010 sebesar 6,1 persen. Pertumbuhan terjadi di berbagai sektor ekonomi. Negara sendiri telah mengatur hak-hak dan kewajiban yang berhak didapatkan oleh buruh atau tenaga kerja dalam Undang-Undang, yaitu
Undang-Undang Ketenagakerjaan Nomor 13 Tahun 2003.

Namun, jika kita melihat lebih jauh realita sosial terkait dengan kesejahteraan buruh di Indonesia menunjukkan bahwa masih banyak buruh di Indonesia yang lemah dan miskin, serta hak-hak dan kebutuhannya tidak terpenuhi. Masih banyak upah buruh yang tidak mencukupi untuk kebutuhan sehari-hari dan kebutuhan keluarganya, serta rentan di-PHK, bahkan sulitnya mencari pekerjaan akibat kondisi tempat kerja yang dirasa tidak nyaman.

Permasalahan buruh dari masa ke masa tidak pernah selesai. Mulai dari masalah perlindungan, kesejahteraan, pengupahan, pembinaan, dan bahkan pengawasan dalam ketenagakerjaan. Banyak hal yang mempengaruhi permasalahan tersebut, salah satunya adalah lemahnya pemerintah dalam mengimplementasikan UndangUndang ketenagakerjaan. Faktor lain yang 


\begin{tabular}{|c|c|c|c|c|}
\hline $\begin{array}{c}\text { Prosiding Penelitian \& } \\
\begin{array}{c}\text { Pengabdian Kepada } \\
\text { Masyarakat }\end{array}\end{array}$ & $\begin{array}{c}\text { e ISSN : 2581-1126 } \\
\text { p ISSN : 2442-448X }\end{array}$ & Vol 5, No: 2 & Hal: $124-131$ & Juli 2018 \\
\hline
\end{tabular}

mempengaruhi tidak selesainya masalah tersebut adalah kebutuhan buruh yang terus meningkat.

Hukum perburuhan atau ketenagakerjaan adalah bagian dari hukum berkenaan dengan pengaturan hubungan perburuhan baik bersifat perseorangan maupun kolektif. Hukum perburuhan terfokus pada buruh yang melakukan pekerjaan dalam suatu hubungan subordinatif (dengan pengusaha atau majikan) (Soepomo, 1980).

Menurut Sudono, 1997, hubungan perburuhan tidak hanya dua pihak saja, yaitu pengusaha dan buruh saja, melainkan langsung terkait dalam proses produksi. Namun, akibat dari perkembangan zaman, hubungan perburuhan diartikan secara luas, sehingga tidak hanya menyangkut buruh dan pengusaha, melainkan juga pemerintahan dan masyarakat. Negara merupakan suatu instansi yang berwenang, sehingga negara merupakan faktor penting dalam hukum perburuhan modern. Keikutsertaan negara atau pemerintah, mewajibkan negara untuk melakukan segala sesuatu agar pekerja atau buruh tidak dilakukan semena-mena, baik perseorangan atau kolektif (Soepomo, 1999).

Hukum ketenagakerjaan secara langsung berkaitan dengan hubungan kerja yang berupa jaminan sosial buruh, serta peraturan-peraturan mengenai badan-badan dan organisasi di lapangan perburuhan (Koesparmono, 2004). Dengan demikian keterkaitan pemerintah dalam hubungan perburuhan atau ketenagakerjaan adalah sebagai pihak yang melakukan pengaturan dalam segala aspek yang berkaitan dengan ketenagakerjaan.

Segala bentuk aturan dalam lingkup ketenagakerjaan salah satunya bertujuaan untuk mensejahterakan pekerja/buruh. Pada pasal 100 Undang-Undang Ketenagakerjaan dijelaskan mengenai jenis dan kriteria fasilitas kesejahteraan untuk pekerja/buruh. Bentuk fasilitas tersebut dapat berupa penyediaan seragam kerja, penyediaan peralatan dan perlengkapan kerja, pengupahan yang layak, pemberian pengarahan tentang kesehatan dan keselamatan kerja, pemberian tunjangan kesehatan, uang lembur jika terdapat kerja lembur, dan pemberian tunjangan hari raya (THR).
Namun kenyataannya masih banyak buruh yang belum menerima hak THR Keagamaannya atau Perusahaan yang tidak menjalankan kewajibannya dalam membayarkan THR Keagamannya. Salah satunya adalah perusahaan menggunakan tenaga kerja buruh kontrak, dengan alasan status tersebut, perusahaan tidak bersedia memberikan THR walaupun pekerja tersebut telah bekerja selama bertahun-tahun. Cara lainnya agar perusahaan tidak membayar THR sesuai ketentuan adalah dengan memanfaatkan ketidaktahuan pekerja atau buruh tentang hak THR dengan memberikan hadiah di Hari Raya dengan bingkisan pakaian, makanan, buah-buahan yang jika dihitung totalnya ternyata kurang dan tidak sesuai dengan ketentuan.

Penelitian ini dilakukan untuk menampilkan profil buruh K3L di zona 2 Universitas Padjadjaran

\section{Metode Penelitian}

Metode penelitian yang digunakan dalam tulisan ini adalah metode kuantitatif. Metode penelitian kuantitatif digunakan untuk menjawab masalah penelitian yang berkaitan dengan data berupa angka dan program statistik. Pendekatan deskriptif dilakukan untuk memberikan gambaran yang lebih detail mengenai suatu gejala atau fenomena. Metode pengumpulan data yang digunakan adalah melalui kuesioner dengan pengambilan sampel secara random.

\section{Pengertian Buruh}

Pada zaman feodal atau jaman penjajahan Belanda dulu, yang dimaksud dengan buruh adalah orangorang pekerja "kasar" seperti kuli, mandor, tukang dan lain-lain. Orang-orang tersebut oleh Pemerintah Belanda disebut dengan blue collar (berkerah biru), sedangkan orang-orang yang mengerjakan pekerjaan "halus" seperti pegawai administrasi disebut white collar (berkerah putih) (Horton, 1992) . Namun, seiring dengan perkembangan zaman, mereka tidak ingin lagi disebut sebagai buruh, terutama pekerja administrasi, sehingga dibuat istilah baru dan mengacu pada Undang-Undang Dasar Negara Republik Tahun 1945. 


\begin{tabular}{|c|c|c|c|c|}
\hline $\begin{array}{c}\text { Prosiding Penelitian \& } \\
\begin{array}{c}\text { Pengabdian Kepada } \\
\text { Masyarakat }\end{array}\end{array}$ & $\begin{array}{c}\text { e ISSN : 2581-1126 } \\
\text { p ISSN : 2442-448X }\end{array}$ & Vol 5, No: 2 & Hal: $124-131$ & Juli 2018 \\
\hline
\end{tabular}

Menurut Undang-Undang Nomor 13 Tahun 2003 tentang Ketenagakerjaan pasal 1 ayat 3, pekerja/buruh adalah setiap orang yang bekerja dengan menerima upah atau imbalan dalam bentuk lain. Sedangkan menurut KBBI 2016 , buruh adalah orang yang bekerja untuk orang lain dengan mendapat upah. Secara umum, buruh dapat didefinisikan sebagai orang yang bekerja untuk orang lain, baik perseorangan atau lembaga, yang menerima upah atau imbalan sebagai hasil kerja.

\section{Pengertian Kesejahteraan}

Dalam membahas tingkat analisis kesejahteraan, kesejahteraan tersebut meliputi, keamanan, keselamatan dan kemakmuran. Menurut W.J.S. Poerwadarminta, 1984, pengertian sejahtera adalah suatu keadaan yang aman, sentosa, dan makmur. Undang-Undang Republik Indonesia Nomor 13 tahun 1998 menyebutkan, kesejahteraan sosial adalah suatu tata kehidupan dan penghidupan sosial baik material maupun spiritual yang diliputi oleh rasa keselamatan, kesusilaan, ketentraman lahir dan batin yang memungkinkan bagi setiap warga negara untuk mengadakan pemenuhan kebutuhan jasmani, rohani, dan sosial yang sebaik-baiknya bagi diri, keluarga, serta masyarakat dengan menjunjung tinggi hak dan kewajiban asasi manusia sesuai dengan pancasila.

Merujuk pada UU Ketenagakerjaan No. 13 Tahun 2003, kesejahteraan pekerja/buruh adalah suatu pemenuhan kebutuhan atau keperluan yang bersifat jasmaniah dan rohaniah, baik selama maupun di luar hubungan kerja, yang secara langsung dan tidak langusng dapat mempertinggi produktivitas kerja. Faktor-faktor yang mempengaruhi kesejahteraan pekerja/buruh dalam rangka peningkatan kinerjanya adalah faktor yang berhubungan dengan jaminan serta kesejahteraan pekerja/buruh yang meliputi sistem besarnya gaji, jaminan sosial, macam-macam tunjangan, lingkungan kerja, fasilitas yang diberikan, promosi, dan sebagainya (Dessler, 1997).

\section{Tunjangan Hari Raya (THR)}

Menurut Peraturan Menteri Ketenagakerjaan Republik Indonesia Nomor 6 Tahun 2016 tentang Tunjangan Hari Raya Keagamaan bagi Pekerja/Buruh di Perusahaan, pada Bab I Pasal 1 ayat 1 , Tunjangan Hari Raya Keagamaan yang selanjutnya disebut THR Keagamaan adalah pendapatan non upah yang wajib dibayarkan oleh Pengusaha kepada Pekerja/Buruh atau keluarganya menjelang Hari Raya Keagamaan. Selanjutnya pada pasal 2 ayat 1, dijelaskan bahwa THR Keagamaan diberikan kepada pekerja/buruh yang telah mempunyai masa kerja 1 (satu) bulan secara terus menerus atau lebih. THR Keagamaan tersebut diberikan kepada pekerja/buruh yang mempunyai hubungan kerja dengan Pengusaha berdasarkan perjanjian kerja waktu tidak tertentu atau perjanjian kerja waktu tertentu. THR Keagamaan diberikan sekali dalam setahun sesuai dengan Hari Raya Keagamaan masing-masing Pekerja/Buruh.

Hari Raya Keagamaan yang dimaksud adalah Hari Raya Idul Fitri bagi pekerja/buruh yang beragama Islam, Hari Raya Natal bagi pekerja/buruh yang beragama Kristen Katholik dan Kristen Protestan, Hari Raya Nyepi bagi pekerja/buruh yang beragama Hindu, Hari Raya Waisak bagi pekerja/buruh yang beragama Budha, dan Hari Raya Imlek bagi pekerja/buruh yang beragama Konghucu. Pemberian THR Keagamaan sebagai bentuk kepedulian perusahaan kepada karyawan agar dapat memenuhi kebutuhan dana ekstra di Hari Raya Keagamaan.Hasil

Penelitian ini dilakukan melalui wawancara dengan pertanyaan yang sudah disiapkan sebelumnya terhadap beberapa pekerja/buruh K3L di zona 2 yang bekerja di Universitas Padjadjaran, Kecamatan Jatinangor, Sumedang. Berikut adalah hasil dari wawancara tersebut.

Tabel 1. Distribusi Responden Berdasarkan Jenis Kelamin

\begin{tabular}{|l|l|c|c|c|}
\hline No. & $\begin{array}{c}\text { Jenis } \\
\text { Kelamin }\end{array}$ & Jawaban & $\begin{array}{c}\text { Frekue } \\
\text { nsi }\end{array}$ & $\begin{array}{c}\text { Persent } \\
\text { asi }\end{array}$ \\
\hline 1. & \multirow{2}{*}{$\begin{array}{l}\text { Jenis } \\
\text { Kelamin }\end{array}$} & $\begin{array}{l}\text { a.Peremp } \\
\text { uan }\end{array}$ & 12 & $92,3 \%$ \\
\cline { 3 - 5 } & b.Laki-laki & 1 & $7,7 \%$ \\
\hline
\end{tabular}

Sumber: Hasil Penelitian 2018 


\begin{tabular}{|c|c|c|c|c|}
\hline $\begin{array}{c}\text { Prosiding Penelitian \& } \\
\text { Pengabdian Kepada } \\
\text { Masyarakat }\end{array}$ & $\begin{array}{c}\text { e ISSN : 2581-1126 } \\
\text { p ISSN : 2442-448X }\end{array}$ & Vol 5, No: 2 & Hal: $124-131$ & Juli 2018 \\
\hline
\end{tabular}

Berdasarkan jenis kelamin, mayoritas pekerja K3L adalah perempuan. Sementara itu, untuk usia pegawai $\mathrm{K} 3 \mathrm{~L}$ yang berperan sebagai responden, lebih dari $92 \%$ berada di kategori usia $>34$ tahun sebagaimana tergambar dalam tabel 2 berikut ini:

Tabel 2. Distribusi Responden Berdasarkan Umur

\begin{tabular}{|c|c|c|c|c|}
\hline No & Umur & Jawaban & Frekuensi & Persentasi \\
\hline 1. & Umur & $\begin{array}{c}20-34 \\
\text { Tahun }\end{array}$ & 1 & $7,7 \%$ \\
\cline { 4 - 5 } 2. & $\begin{array}{c}>34 \\
\text { Tahun }\end{array}$ & 12 & $92,3 \%$ \\
\hline
\end{tabular}

Sumber: Hasil Penelitian 2018

Usia >34 adalah termasuk dalam kategori usia produktif, sehingga bukanlah hal yang aneh jika para pekerja itu mendaftar sebagai pekerja K3L karena gaji yang lebih besar dari bidang pekerjaan mereka sebelumnya.

Tabel 3. Distribusi Responden Berdasarkan Pendidikan Terakhir

\begin{tabular}{|c|c|c|c|c|}
\hline No. & $\begin{array}{c}\text { Pendidi } \\
\text { kan } \\
\text { Terakhi } \\
\mathbf{r}\end{array}$ & $\begin{array}{c}\text { Jawaba } \\
\mathbf{n}\end{array}$ & $\begin{array}{c}\text { Frekue } \\
\text { nsi }\end{array}$ & $\begin{array}{c}\text { Persent } \\
\text { asi }\end{array}$ \\
\hline 1. & \multirow{2}{*}{$\begin{array}{c}\text { Pendidi } \\
\text { kan } \\
\text { 2. }\end{array}$} & $\begin{array}{c}\text { SD/Sede } \\
\text { rajat }\end{array}$ & 11 & $84,6 \%$ \\
\cline { 1 - 1 } 3. & $\begin{array}{c}\text { SMP/Se } \\
\text { derakhi } \\
\text { derajat }\end{array}$ & $\begin{array}{c}\text { SMA/Se } \\
\text { derajat }\end{array}$ & 1 & $7,7 \%$ \\
\hline
\end{tabular}

Sumber: Hasil Penelitian 2018

Berdasarkan hasil wawancara, sekitar $84,6 \%$ dari responden memiliki pendidikan terakhir $\mathrm{SD} /$ Sederajat, ini berarti tingkat pendidikan mempengaruhi pekerjaan yang didapat.

Sementara itu, berdasarkan hasil wawancara, seluruh responden berstatus menikah, dan ini berarti para perempuan berusia produktif yang bekerja di K3L Unpad adalah mayoritas para istri yang membantu suami mereka untuk mendapatkan penghasilan yang dapat menunjang keadaan ekonomi keluarga mereka.
Tabel 4. Distribusi Responden Berdasarkan Tempat Tinggal

\begin{tabular}{|c|c|c|c|c|}
\hline No & $\begin{array}{c}\text { Tempat } \\
\text { Tinggal } \\
\text { (Desa) }\end{array}$ & Jawaban & $\begin{array}{c}\text { Frekue } \\
\text { nsi }\end{array}$ & $\begin{array}{l}\text { Persent } \\
\text { asi }\end{array}$ \\
\hline 1. & \multirow{4}{*}{$\begin{array}{l}\text { Tempat } \\
\text { Tinggal } \\
\text { (Desa) }\end{array}$} & Cileles & 6 & $46,2 \%$ \\
\hline 2. & & Jatimukti & 2 & $15,4 \%$ \\
\hline 3. & & Cipacing & 2 & $15,4 \%$ \\
\hline 4. & & Cilayung & 3 & $23 \%$ \\
\hline
\end{tabular}

Sumber: Hasil Penelitian 2018

Berdasarkan hasil wawancara oleh responden, pekerja/buruh K3L di Zona 2 Universitas Padjadjaran, tempat tinggalnya tersebar dibeberapa wilayah di Jatinangor, sebanyak $46,2 \%$ bertempat tinggal di Cileles ini berarti banyak pekerja/buruh K3L yang bertempat tinggal jauh dari lingkungan Unpad.

Tabel 6. Distribusi Responden Berdaasarkan Lama Bekerja

\begin{tabular}{|c|c|c|c|c|}
\hline No. & $\begin{array}{c}\text { Lama } \\
\text { Bekerja }\end{array}$ & Jawaban & $\begin{array}{c}\text { Freku } \\
\text { ensi }\end{array}$ & Persentasi \\
\hline 1. & $\begin{array}{c}\text { Lama } \\
\text { Bekerja }\end{array}$ & $\begin{array}{c}1-2 \\
\text { Tahun }\end{array}$ & 1 & $7,7 \%$ \\
\cline { 4 - 5 } 2. & & $\begin{array}{c}2-<3 \\
\text { Tahun }\end{array}$ & 2 & $15,4 \%$ \\
\cline { 4 - 5 } 3. & $\begin{array}{c}>3 \\
\text { Tahun }\end{array}$ & 10 & $76,9 \%$ \\
\hline
\end{tabular}

Sumber: Hasil Penelitian 2018

Berdasarkan hasil wawancara dengan pekerja/buruh K3L Universitas Padjadjaran, lama responden bekerja sebagai pekerja/buruh K3L mayoritas adalah lebih dari 3 tahun. Ini berarti bahwa lingkungan Unpad memliki kondisi yang nyaman, selain dari itu, sulitnya mencari pekerjaan dan alasan ekonomi membuat pekerja/buruh K3L tidak resign dari pekerjaannya.

Respon para pekerja K3L Unpad berkaitan dengan pertanyaan upah yang diterima, responden seluruhnya menjawab bahwa mereka mendapatkan gaji sekitar Rp.700.000,00 Rp.799.000,00/bulan. Untuk lebih spesifiknya, mereka menerima gaji sebesar Rp.750.000,00/bulan, yang dibayarkan oleh pihak Unpad.Besaran ini tidak sesuai dengan besaran 


\begin{tabular}{|c|c|c|c|c|}
\hline $\begin{array}{c}\text { Prosiding Penelitian \& } \\
\text { Pengabdian Kepada } \\
\text { Masyarakat }\end{array}$ & $\begin{array}{c}\text { e ISSN : 2581-1126 } \\
\text { p ISSN : 2442-448X }\end{array}$ & Vol 5, No: 2 & Hal: $124-131$ & Juli 2018 \\
\hline
\end{tabular}

nilai gaji UMK/UMR untuk wilayah Kabupaten Sumedang yang sebesar Rp. 2.678.028,99

Tabel 8. Apakah ada Tunjangan Hari Raya (THR)?

\begin{tabular}{|c|c|c|c|c|}
\hline No. & $\begin{array}{c}\text { Apakah } \\
\text { ada } \\
\text { Tunjangan } \\
\text { Hari Raya } \\
\text { (THR)? }\end{array}$ & $\begin{array}{c}\text { Jawaban } \\
\text { (dalam } \\
\text { Rupiah) }\end{array}$ & Frekuensi & Persentasi \\
\hline 1. & \multirow{3}{*}{$\begin{array}{l}\text { Apakah } \\
\text { ada } \\
\text { Tunjangan } \\
\text { Hari Raya } \\
\text { (THR)? }\end{array}$} & Rp.0 & 1 & $7,7 \%$ \\
\hline 2. & & $\begin{array}{c}\text { Rp.500 - } \\
1.000 \\
\end{array}$ & 10 & $76,9 \%$ \\
\hline 3. & & Sembako & 2 & $15,4 \%$ \\
\hline
\end{tabular}

Sumber: Hasil Penelitian 2018

Berdasarkan hasil wawancara, pekerja/buruh K3L Zona 2 Universitas Padjadjaran, mengatakan sebanyak $7,7 \%$ responden mengatakan bahwa responden sama sekali tidak mendapatkan THR Keagamaan, sebanyak $76,9 \%$ responden mengatakan bahwa ia menerima THR Keagamaan menerima THR Keagamaan sebesar Rp.500.000,00 - Rp.1.000.000,00, dan sekitar 15,4\% responden menerima sembako sebagai THR Keagamaan yang didapatkan dari pihak Unpad.Tabel ini menunjukkan keragaman pemberian THR yang diterima oleh setiap responden, dan menjadi bahan yang penting untuk didalami lebih lanjut mengapa terjadi perbedaan tersebut.

\section{Pembahasan}

Pekerja/buruh adalah orang yang bekerja untuk orang lain, baik untuk orang perseorangan, lembaga, ataupun perusahaan, yang mendapatkan upah atau imbalan atas hasil kerjanya. Pekerja/buruh bekerja untuk berbagai alasan, bisa jadi pekerjaan tersebut merupakan penghasilan utama, atau sekedar hanya ingin membantu perekonomian keluarga. Pekerja/Buruh K3L di Universitas Padjadjaran, bertugas untuk menjaga kebersihan lingkungan Unpad. Pekerja/buruh K3L Unpad dibagi menjadi beberapa zona dengan tugas yang berbeda-beda. Ada yang bertugas membersihkan pekarangan fakultas, dan ada yang bertugas membersihkan jalanan.

Petugas K3L Unpad, memiliki tempat tinggal yang tersebar di berbagai daerah di Jatinangor, seperti
Desa Jatimukti, Desa Cileles, Desa Cilayung, Desa Cipacing, dan Desa Cilayung. Untuk menjadi petugas K3L Unpad, responden menyerahkan surat lamaran kepada pihak Unpad, dan menunggu kurang dari seminggu untuk dapat bekerja. Tingkat pendidikan yang dimiliki oleh pekerja/buruh K3L sendiri beragam, namun, rata-rata dari responden memiliki tingkat pendidikan SD/Sederajat. Banyak dari responden mengatakan tidak dapat melanjutkan pendidikannya karena faktor ekonomi. Selain pendidikan, umur responden juga beragam, namun responden di Zona 2 paling banyak berada di rentang usia $>34$ Tahun. Petugas K3L di Zona 2 rata-rata berjenis kelamin perempuan dan berperan sebagai istri dalam keluarga.

Berdasarkan hasil wawancara, banyak dari responden mengatakan telah lama bekerja sebagai pekerja/buruh K3L di Unpad. Mereka bekerja untuk membantu perekonomian keluarga. Hal ini dikarenakan karena kebutuhan hidup yang semakin meningkat, menjadikan responden yang bertugas sebagai istri dalam keluarga juga berperan dalam membantu perekenomian keluarga.

Sebagai pekerja/buruh, K3L tentunya memiliki hak untuk mendapatkan upah serta jaminan sosial lainnya, seperti jaminan kesehatan, pemberian THR Kegamaan, fasilitas peralatan dan perlengkapan untuk bekerja, seragam, dan masih banyak lagi. K3L bekerja dari pukul 07.00 sampai dengan pukul 11.30, dengan gaji yang diberikan sekitar Rp.750.000,00. Namun, para pekerja/buruh K3L mengatakan mereka tidak mendapatkan jaminan kesehatan, dan juga terkadang peralatan dan perlengkapan kerja seperti sapu, dan karung telat diberikan, sehingga pekerja/buruh K3L harus membeli sendiri. Selain itu, hak yang didapatkan pekerja/buruh K3L adalah THR Keagamaan.

THR Keagamaan adalah pendapatan non upah yang wajib dibayarkan oleh Pengusaha kepada Pekerja/Buruh atau keluarganya menjelang Hari Raya Keagamaan. THR Keagamaan diterima setahun sekali sesuai Hari Raya yang dirayakan oleh pekerja/buruh.besaran THR yang diterima, ditetapkan dalam Peraturan Menteri 


\begin{tabular}{|c|c|c|c|c|}
\hline $\begin{array}{c}\text { Prosiding Penelitian \& } \\
\begin{array}{c}\text { Pengabdian Kepada } \\
\text { Masyarakat }\end{array}\end{array}$ & $\begin{array}{c}\text { e ISSN : 2581-1126 } \\
\text { p ISSN : 2442-448X }\end{array}$ & Vol 5, No: 2 & Hal: $124-131$ & Juli 2018 \\
\hline
\end{tabular}

Ketenagakerjaan No.6 Tahun 2016 pada Bab 2, Pasal 3 ayat 1 , pekerja/buruh yang telah mempunyai masa kerja 12 (dua belas) bulan secara terus menerus atau lebih, diberikan sebesar 1 (satu) bulan upah. Sedangkan bagi pekerja/buruh yang mempunyai masa kerja 1 (satu) bulan secara terus menerus, namun kurang dari 12 (dua belas) bulan, diberikan secara proporsional sesuai dengan masa kerja, dengan perhitungan: $x 1$ bulan upah.

Berdasarkan hasil wawancara yang dilakukan dengan responden, yaitu petugas K3L Zona 2 Unpad, rata-rata responden bekerja menjadi petugas K3L lebih dari 1 tahun dengan gaji yang diterima sebesar Rp.750.000,00. Namun, jika dilihat pada tabel 8 (ditribusi responden berdasarkan THR), masih terdapat pekerja/buruh yang belum mendapatkan THR, dan masih terdapat pekerja/buruh yang mendapatkan THR berupa sembako, bukan berupa uang. Dapat diartikan, pemberian THR kepada pekerja/buruh K3L di Zona 2 Unpad belum merata. Memang ratarata responden telah mendapatkan THR mereka secara penuh, namun masih terdapat beberapa orang yang belum menerima THR mereka, terlebih mereka telah bekerja sebagai petugas K3L lebih dari 1 (tahun).

Dalam wawancara juga responden menuturkan, baru beberapa tahun mereka mendapatkan THR, sebelumnya mereka belum mendapatkan THR, meski begitu, THR yang seharusnya didapat oleh semua pekerja/buruh nyatanya tidak semua mendapat THR. Dilihat dari THR Keagamaan, pada dasarnya, beberapa pekerja/buruh sudah menerima THR sesuai dengan ketentuan, yaitu sebesar 1 (satu) bulan gaji. Yang artinya, hampir semua pekerja/buruh sudah mendapatkan haknya dalam menerima THR Keagamaan, sebagai bentuk kewajiban perusahaan. Walaupun begitu, pihak Unpad juga harus meratakan pemberian THR Keagamaan pada para pekerjanya, sebagai salah satu kewajiban yang harus dijalankan perusahaan dalam pemenuhan pemberian hak berupa fasilitas kesejahteraan yang diterima oleh pekerja/buruh K3L yang telah berperan menjaga kebersihan lingkungan Unpad.

\section{Kesimpulan}

Pekerja/buruh mempunyai hak dan kewajiban sebagai buruh, mendapatkan THR Keagamaan dari perusahaan adalah salah satu dari banyak hak yang diterima oleh pekerja/buruh. THR Keagamaan ini diterima oleh pekerja/buruh 1 (satu) kali dalam 1 (satu) tahun. Pemberian THR disesuaikan dengan Hari Raya yang dijalankan oleh Pekerja/buruh. Namun, pada kenyataannya, masih banyak perusahaan yang mencari cara agar lepas dari kewajibannya memberikan THR Keagamaan untuk para pekerja/buruh, salah satunya adalah memberikan sembako, atau bingkisan buah-buah, makanan, pakaian, yang jika dijumlahkan tidak sesuai dengan ketentuan.

Sebagai pekerja/buruh, petugas K3L zona 2 Universitas Padjadjaran juga berhak mendapatkan THR. Walaupun baru beberapa tahun terakhir pemberian THR diterapkan, ternyata masih terdapat beberapa pekerja yang tidak menerima THR Keagamaannya, atau mendapatkan THR berupa sembako saja, padahal jika mengetahui ketentuan, THR yang diterima oleh pekerja adalah sebesar upah 1 (satu) bulan dari buruh tersebut. Namun, dapat dikatakan, bahwa sebagian besar dari petugas $\mathrm{K} 3 \mathrm{~L}$ telah mendapatkan haknya dalam menerima THR Keagamaan.

\section{Daftar Pustaka}

\section{Buku}

Dessler, G. (1997). Manajemen Sumber Daya Manusia. Jakarta: PT. Prenhallindo.

Dr. Wahidmurni, M. (2017). PEMAPARAN METODE PENELITIAN KUANTITATIF. 1-16.

Horton, P. B., \& Hunt, C. L. (1992). Sosiologi. (A. Ram, Penerj.) Jakarta: Penerbit Erlangga.

Idrus, M. (2009). Metode Penelitian IImu Sosial Pendekatan Kualitatif dan Kuantitatif . Yogyakarta: Penerbit Erlangga.

Irsan, K. (2004). Hukum ketenagakerjaan suatu pengantar. Jakarta: Komisi Nasional HAM Indonesia. 


\begin{tabular}{|c|c|c|c|c|}
\hline $\begin{array}{c}\text { Prosiding Penelitian \& } \\
\begin{array}{c}\text { Pengabdian Kepada } \\
\text { Masyarakat }\end{array}\end{array}$ & $\begin{array}{c}\text { e ISSN : 2581-1126 } \\
\text { p ISSN : 2442-448X }\end{array}$ & Vol 5, No: 2 & Hal: $124-131$ & Juli 2018 \\
\hline
\end{tabular}

KBBI. (2016). Kamus Besar Bahasa Indonesia Edisi V.

Menteri Ketenagakerjaan Republik Indonesia. (2016). PERATURAN MENTERI KETENAGAKERJAANREPUBLIK INDONESIA NOMOR 6 TAHUN 2016 TENTANG TUNJANGAN HARI RAYA KEAGAMAAN BAGI PEKERJA/BURUH DI PERUSAHAAN.

Poerwadarminta. (1984). Kamus Umum Bahasa Indonesia. Jakarta: Balai Pustaka.

Presiden Republik Indonesia . (2003). UNDANGUNDANG REPUBLIK INDONESIA NOMOR 13 TAHUN 2003 TENTANG KETENAGAKERJAAN.

Soepomo, I. (1980). Pengantar Hukum Perburuhan, cetakan ke III. Jakarta: Penerbit Djambatan.

Sudono, A. (1997). Perburuhan dari masa ke masa. Jakarta: PT. Pustaka Cidesindo.

\section{Jurnal}

Effendi, W. R. (2017, Januari). HAK ASASI MANUSIA : STUDI HAK-HAK BURUH DI INDONESIA. 6(1), 106-125.

Hendrastomo, G. (2010). Menakar Kesejahteraan Buruh: Memperjuangkan Kesejahteraan Buruh diantara Kepentingan Negara dan Korporasi. Jurnal Informasi, 16(2), 1 - 17.

Kusumawati, C. I. (2013). ANALISIS PENGARUH TINGKAT KESEJAHTERAAN KARYAWAN TERHADAP KINERJA KARYAWAN (Studi kasus pada RSUD dr. Moewardi di Surakarta).

Natalia, I. I. (2016). KAJIAN TINGKAT KESEJAHTERAAN DAN PENDIDIKAN ANAK PETANI SALAK PONDOH DI DESA PEKANDANGAN KECAMATAN BANJARMANGU KABUPATEN BANJARNEGARA. 1 - 42.
Randi. (2017). BURUH VS PERUSAHAAN (Studi Kasus Konflik Buruh/Pekerja Driver GoJek dengan PT Go-Jek Indonesia). Social Work Journal, 7(2), 1 - 79.

Rosadi, M. I., Antikowati, \& Indrayati, R. (2013). IMPLEMENTASI PEMBAYARAN TUNJANGAN HARI RAYA KEAGAMAAN BAGI PEKERJA TIDAK TETAP DI PTP NUSANTARA XI (PERSERO) - P.G. DJATIROTO BERDASARKAN PERMENAKER NOMOR 04/MEN/1994. 1 - 6.

Sejati, A. N., \& Wijaya, M. (2015). PERAN BURUH DALAM KESEJAHTERAAN SOSIAL PERUSAHAAN PT. SENANG KHARISMA TEXTILE (Studi Kasus Kewajiban, Upah, Jaminan Sosial, dan Fasilitas Kesejahteraan Buruh di PT. Senang Kharisma Textile, Kecamatan Jaten, Kabupaten Karanganyar, Solo). Jurnal Sosiologi, 30(1), 17 - 26.

Siregar, N. R., Suryana, A. A., Rostika, R., \& Nurhayati, A. (2017). ANALISIS TINGKAT KESEJAHTERAAN NELAYAN BURUH ALAT TANGKAP GILL NET DI DESA SUNGAI BUNTU KECAMATAN PEDES KABUPATEN KARAWANG. Jurnal Perikanan dan Kelautan, VIII (2), 112-117.

Sutrisno, L. B., Budiono, A. R., \& H.T., R. D. (2015). JENIS DAN KRITERIA FASILITAS KESEJAHTERAAN UNTUK PEKERJA/BURUH DALAM PASAL 100 UNDANG-UNDANG REPUBLIK INDONESIA NOMOR 13 TAHUN 2003 TENTANG KETENAGAKERJAAN. 119.

Taufik, M. A. (2015). KEBERADAAN OUTSOURCING PT. PRIMA KARYA SARANA SEJAHTERA (PKSS) BANDUNG DALAM MENYALURKAN PARA PEKERJA KE BANK RAKYAT INDONESIA(BRI) CABANG CIANJUR DIHUBUNGKAN DENGAN UNDANG-UNDANG NO 13 TAHUN 2003 TENTANG KETENAGAKERJAAN. 


\begin{tabular}{|c|c|c|c|c|}
\hline $\begin{array}{c}\text { Prosiding Penelitian \& } \\
\text { Pengabdian Kepada } \\
\text { Masyarakat }\end{array}$ & $\begin{array}{c}\text { e ISSN : 2581-1126 } \\
\text { p ISSN : 2442-448X }\end{array}$ & Vol 5, No: 2 & Hal: $124-131$ & Juli 2018 \\
\hline
\end{tabular}

Utomo, I. S. (2005). SUATU TINJAUAN TENTANG

TENAGA KERJA BURUH DI INDONESIA.

Journal The WINNERS , 83 - 93. 